\title{
OS DESAFIOS PARA A ELIMINAÇÃO DA PENA DE MORTE NO JAPÃO
}

Lilian Yamamoto ${ }^{1}$

Resumo: A pena de morte esteve presente na maior parte da história do Japão. Na contramão da maioria dos países desenvolvidos não há perspectivas para que ela seja abolida em curto ou em médio prazo do sistema penal japonês. Esse artigo pretende investigar quais as razões para a predominância do posicionamento favorável a sua retenção, em especial, a opinião pública e a política governamental, sem antes analisar a evolução dos seus métodos de execução, a discussão da sua constitucionalidade, bem como os argumentos retencionistas. Ao final, objetivase demonstrar que as pesquisas de opinião pública podem gerar resultados de acordo com o interesse de quem as conduz.

Palavras-chave: pena de morte, direito penal, evolução histórica, opinião pública, abolição

Abstract: Death penalty has been present in most part of Japanese history. In the opposite direction of the majority of the developed countries, there is not any short-medium term perspective it will be abolished from the Japanese penal system. This article intends to investigate what are the reasons for the predominance of its favorable position and its retention, in special, the public opinion and governmental politics. Before that, it will analyze the evolution of its execution methods, a discussion of its constitutionality, as well as its retentionist reasonings. Eventually, it

1. Pós-doutoranda do Programa de Pós-Graduação em Língua, Literatura e Cultura Japonesa da Faculdade de Filosofia, Letras e Ciências Humanas da Universidade de São Paulo (USP), São Paulo, Brasil; lilianmitsuko@yahoo.it 
aims to demonstrate that the public opinion polls can generate results according to the interests of those who carry them out.

Keywords: death penalty, penal law, historical evolution, public opinion, abolition

\section{Introdução}

O Japão é um dos poucos países desenvolvidos que mantêm a pena de morte no seu sistema penal, em um posicionamento oposto à tendência mundial em aboli-la nas últimas décadas, movimento que provém da evolução do discurso e instrumentos de proteção dos direitos humanos após o final da Segunda Guerra Mundial, em especial, o princípio da dignidade da vida humana. Estima-se que mais de dois terços dos países no mundo já eliminaram tal pena dos seus sistemas legais (AMNESTY INTERNATIONAL, 2015, p.64). Nos últimos 50 anos, o entendimento sobre a pena de morte mudou drasticamente e os instrumentos de direito internacional acompanharam essa tendência (ABE, 2008, p.79), mas o início do movimento remonta ao século XVIII na Europa e em alguns estados dos Estados Unidos (CHUKYO HÔGAKU, 1987, p.142). Apesar do Japão ainda manter a pena ${ }^{2}$, nota-se uma diminuição visível no número de execuções nos últimos anos. Mas, até que ponto o país segue a tendência internacional em se tratando da temática de direitos humanos? O Japão ratificou o Pacto de Direitos Civis e Políticos (1966) em 1979, sem reservas. Apesar deste instrumento no seu art. 6 (2) não vetar explicitamente a pena de morte, estipula que nos países que não a aboliram a sua aplicação deverá ser feita para "os crimes mais graves", além de prever critérios para a proteção de privação do direito à vida (art. 6(1)), através de tribunais competentes, previsão de procedimentos de apelação e tratamento humano dos condenados. Entretanto, o art. 6(6) prevê que "Não se poderá invocar disposição alguma do presente artigo para retardar ou impedir a abolição da pena de morte por um Estado parte do presente Pacto.” O Japão, no entanto, não ratificou o instrumento com vistas à Abolição da Pena de Morte, o Segundo Protocolo Facultativo ao Pacto Internacional sobre Direitos Civis e Políticos, o que demonstra o seu posicionamento claro de manutenção de tal pena.

Johnson também acredita que o sigilo das execuções, a ausência de informações a respeito das condições dos presos, bem como o modo de execução dos condenados são fatores que contribuem para que ela goze de um alto índice de aprovação popular

2. Outros países que mantêm a pena de morte em setembro de 2015 são Afeganistão, Antigua e Barbuda, Bahamas, Bahrain, Bangladesh, Barbados, Bielarússia, Belize, Botswana, Chad, China, Comoros, República Democrática do Congo, Cuba, Dominica, Egito, Guiné Equatorial, Etiópia, Gâmbia, Guatemala, Guiné, Guiana, India, Indonésia, Irã, Iraque, Jamaica, Japão, Jordânia, Kuweit, Líbano, Lesoto, Líbia, Malásia, Nigéria,Coréia do Norte, Omã, Paquistão, Palestina, Catar, São Cristóvão e Nevis, Santa Lucia, São Vicente e Grenadinas, Arábia Saudita, Cingapura, Somália, Sudão do Sul, Sudão, Síria, Taiwan, Tailândia, Trinidade e Tobago, Uganda, Emirados Árabes Unidos, Estados Unidos, Vietnã, Yemen, Zimbábue. 
(JOHNSON, 2006, p.112). As notícias de execuções geralmente são vazadas pela mídia, por familiares e advogados das vítimas e o governo é reticente em comentá-las.

A pena de morte esteve presente na maior parte da história japonesa. Diversas formas de execução foram aplicadas no decorrer da história, mas o enforcamento tornouse a única forma de execução pelo decreto Daijokan n.65/1873 (NICHIBENREN). Esta forma de execução passou a ser exclusiva desde 1868 (art. 11 do Código Penal) (SATO, 2006, p.7). Nesse artigo, pretendemos expor a evolução histórica da pena de morte, quais os fatores para o seu enraizamento no Japão, além dos desafios para a sua abolição no contexto social japonês.

\section{Evolução Histórica da Pena de Morte no Japão}

A pena de morte foi a principal sanção penal em grande parte da história japonesa e sofreu grandes variações no seu modo de execução. Durante o século IV, os conceitos chineses de punição começaram a ser introduzidos no sistema legal japonês e a tortura era frequentemente aplicada para extrair confissões nos casos de furtos, seqüestros e assassinatos. A sanção visava a retaliação mais do que a prevenção das ofensas criminais. Nessa época, as punições eram divididas em regulares (shokei) e extraordinárias (junkei). As cinco espécies de shokei eram: chibatadas (chi), surra de vara (jô), encarceramento $(z u)$, banimento $(r u)$ e morte $(s h i)$. A pena capital era executada por enforcamento $(k \hat{o})$ ou decapitação (zan). (SCHMIDT, 2001, p.10)

Em 724 D.C, o edito do imperador Shomu vetava a pena capital, e aboliu de facto a pena em um interstício de 346 anos (entre 810 e 1156 D.C) no Período Heian (794-1185, D.C). Especula-se que tal suspensão ocorreu por influência dos ensinamentos budistas da época que pregavam a preciosidade da vida. Naquele período, o procedimento para a execução da pena exigia o crivo do imperador e assim, tornou-se um costume que ela fosse comutada para deportação do criminoso para um local remoto por uma ordem imperial. (DANDO, 1996, p.7). O retorno da pena capital ocorreu em 1156 D.C e os métodos de execução eram diversos, dependendo da classe social do criminoso. Por exemplo, na classe dos samurais era permitido que se cometesse o hara-kiri ou seppuku, formas de suicídio consideradas como honrosas ao invés de submeterem os guerreiros a uma humilhante decapitação ou enforcamento. A classe dos agricultores, por sua vez, era executada de forma menos digna, por decapitação, enforcamento, crucificação, fogueira ou ferventação. (KIM, 1989, p.274)

Em 1241, foi estabelecido que o homicídio deveria ser punido com a decapitação. (HOMUSHO, [201-], p.2). Durante o Período Kamakura (1185-1333) o decreto de estabelecimento do Bushidô Goseibai-shikimoku (1232 D.C) estabelecia como formas de sanção a pena de morte, o exílio, a detenção, os castigos corporais e o confisco de bens. Na realidade, durante o período com início na Era Kamakura até o final da era Tokugawa (1603-1867), não seria exagero afirmar que a forma principal de punição era a pena de morte. Assim, todos os crimes, desde furtos até homicídios eram punidos com 
a morte, que funcionava como a base principal, fonte para criatividade horripilante das autoridades que usavam uma variedade de práticas que pudessem intensificar a dor nos castigos corporais e criavam "níveis de morte" (JOHNSON, 2006, p.77). Durante o Período Ashikaga ou Muramachi (1392-1490) a pena de morte foi também a escolhida forma de punição básica. As punições assumiram caráter privado e as formas de execução incluíam a crucificação (haritsuke), crucificação invertida (sakasaharitsuke), empalamento (kushizashi), serração (nokohiki), desmembramento por bois (ushizaki), ou por carroça (kurumazaki), fogueira (hiaburi), ferventação (kama-iri), fogueira com o executado atado a lenha (taimatsuaburi), forca (shibarikubi), decapitação (funkei), dentre outros. Durante esse período, uma grande variedade de crimes era punida por pena de morte e a punição era estendida à esposa e aos filhos do criminoso (SCHMIDT, 2001, p.14). Durante o Período Edo (1603-1868) previa-se a decapitação (zankei), crucificação (haritsuke), fogueira (kazai), serrote ${ }^{3}$ (nokogiribiki), exposição $(\text { gokumon })^{4}$ e a simples decapitação (geshinin $)^{5}{ }^{6}$

O serrote era muito aplicado durante o período em que Oda Nobunaga (1534-1582) estava no poder. Após Tokugawa Ieyasu unificar o país, iniciou-se um período pacífico que o seu xogunato proporcionou por dois séculos e meio. Não houve grandes alterações nos códigos penais desde o período Sengoku e os familiares também continuavam a receber punições junto com os culpados. Assim, cada daimyô (o senhor de terras que governava a maior parte do país a partir de suas imensas propriedades de terra hereditárias) promulgava suas próprias leis e poderia levar a cabo as execuções de forma autônoma, sem necessidade da permissão do bakufu (governo do xogunato). Nessas leis herdadas do período Sengoku, a regra máxima era a obediência ao senhor feudal, aos mestres e aos pais. Os crimes que atentassem contra eles eram punidos com grande severidade. Muitos crimes nesse período eram punidos por mutilação nasal ou auricular. No decorrer do século XVIII, tal severidade das penas foi substituída pela mentalidade de Confúcio, que privilegiava os ensinamentos que se tornaram preponderantes ao mesmo tempo em que as punições mais severas se tornaram mais escassas. (STEENSTRUP, 1991, p.151)

Quando o período Tokugawa terminou em 1867 e o império foi restaurado, os reformadores do governo Meiji perceberam a urgência em modernizar todos os aspectos

3. Essa pena, de caráter vingativo, consistia em amarrar o condenado, e fazer um pequeno ferimento no pescoço do condenado, deixando um serrote próximo a ele visando que a família da vítima e os transeuntes serrassem o pescoço do condenado de modo que a sua morte ocorresse de forma lenta. Algumas vezes também penduravam o condenado de cabeça para baixo para que o corpo fosse serrado a partir da zona genital.

4. Após a decapitação do condenado, a cabeça era colocada em cima de uma tábua e deixada em exibição por 3 dias e 2 noites para mostrar ao público a punição do criminoso.

5. É a penalidade considerada como a mais branda porque consistia na decapitação feita por uma espada e não havia outras penalidades adicionais, como a exposição da cabeça por vários dias.

6. HOMUSHO, Wagakuni ni okeru shikeino rekishinitsuite, shiryo 18. Disponível em: http://www.moj. go.jp/keiji1/keiji12_00056.html. Acesso em 20 jun. 2015. 
da sociedade japonesa, incluindo as práticas penais. Assim, os castigos corporais foram extintos, as distinções entre classes na forma de punição foram eliminadas e as execuções mandatórias foram erradicadas. A partir de 1882 as execuções passaram a ocorrer dentro das prisões, deixando de ser um espetáculo público (JOHNSON, 2006, p.79). No início do Período Meiji (1868-1912) remanesciam 5 formas de execução pública: forca, crucificação, fogueira, auto-decapitação (fun) e decapitação. Com a entrada em vigor do Shinritsu Kôryô (1871), que consistia no primeiro código penal estabelecido por Dajôkan, os tipos de execução se reduziram para a forca e a decapitação. O novo código estabeleceu que a maior parte dos crimes seria punida por detenção e trabalho forçado. (SCHMIDT, 2001, p.21).

Atualmente, a forma de execução é a forca (art. 11 (1) do Código Penal de 1907). Não obstante a ausência de justificativa oficial para a redução da forma de execução para um único método, parte da doutrina acredita que a forca tenha sido escolhida como uma forma menos cruel de execução, por provocar menos dor ao executado. Essa explicação não sobrevive às evidências científicas que comprovam que na decapitação, o coração cessa o envio de sangue ao cérebro, o que vem a causar a morte instantânea das células cerebrais no momento em que a cabeça se separa do restante do corpo, ao passo que, no enforcamento, a morte ocorre de maneira mais lenta. Há registro de que a execução mais longa por enforcamento no Japão ocorreu em 37 minutos. (SAKURAI, 2008, p.94). Assim, o motivo talvez não seja de atenuar a crueldade na execução, mas de preservar o corpo para que os familiares e amigos possam receber o corpo intacto. (SAKURAI, 2008, p.95).

O Japão desde então manteve a pena de morte em seus códigos penais, com alguns períodos de suspensão da execução, como entre novembro de 1989 a março de 1993 (NICHIBENREN, 2002, p.4) quando os ministros da Justiça deixaram de assinar os documentos necessários para a execução dos condenados.

\section{A Constitucionalidade da Pena}

A constitucionalidade da pena de morte foi discutida em juízo pela defesa em casos em que o Ministério Público pedia a condenação à morte. Tal fundamentação baseia-se no art. 36 da Constituição promulgada em 1946 que prevê proibição de penas cruéis. Tal artigo prevê que: "A imposição de tortura e punições cruéis por qualquer agente público são absolutamente proibidas". A constitucionalidade da pena foi confirmada pela decisão da Suprema Corte Japonesa em 12 de março 1948, em resposta à defesa que em nível recursal argumentou que "segundo a nova constituição, a pena de morte foi abolida". 
$\mathrm{O}$ artigo $13^{7}$ da Constituição estabelece que todos os indivíduos devem ter o seu direito à vida respeitado. É necessário que isso seja respeitado nas políticas públicas e na legislação. Entretanto, no mesmo artigo, está prevista uma rigorosa limitação que estabelece que esse direito deve ser respeitado desde que não contrarie o bem comum. Assim, se o princípio fundamental do bem comum for desrespeitado, é natural que se entenda que o direito à vida poderá sofrer limitações. Outrossim, de acordo com o art. 31 da Constituição mesmo que esteja previsto o respeito à vida, no procedimento estabelecido pela lei, a sanção que venha a suprimi-lo está previsto de forma explícita. Em outras palavras, a Constituição, tal como em diversos países na atualidade prevê a existência da pena de morte como sanção (...) a defesa do réu baseou-se no argumento de que o art. 36 da Constituição veta de forma absoluta penas cruéis e que a pena de morte seria uma violação à Constituição. Entretanto, não se pode concluir que a pena de morte como sanção, em geral, corresponda de forma direta a uma pena cruel. Mesmo a pena de morte, de forma similar a outras penas, possui uma forma de execução do ponto de vista humanitário (...) reconheceríamos obviamente que é uma pena cruel, se no futuro, por exemplo, fosse feita uma lei que determinasse que os métodos de execução fossem a fogueira, a crucificação, a decapitação com exposição e a ferventação. Nesse caso, realmente, essa lei violaria o dispositivo do art.36 da Constituição. (tradução nossa) (Decisão da Suprema Corte Japonesa de 12 de março de 1948)

Dessa forma, a Suprema Corte entendeu que a pena de morte tem um papel preventivo e promove o bem comum, privilegiando o bem-estar da sociedade, procurando demonstrar que ela preserva a segurança pública e que, portanto, não há violação do art. 36 da Constituição. Outrossim, a Suprema Corte também interpretou que a forma de execução, mais do que a morte em si seria o parâmetro para determinar a crueldade da pena e citou como cruéis os métodos de execução anteriores à era Meiji. Nesse exame do nível de crueldade, porém, negligenciou a consideração sobre o tempo que levava para o condenado morrer uma vez que o enforcamento pode resultar em morte mais lenta do que a decapitação. A forca como forma de execução não foi considerada como cruel pelo Supremo Tribunal como pôde ser confirmado pela decisão de 6 de abril de 1955 em que o Tribunal a compara com os demais métodos de execução praticados em outros países, como o estrangulamento, decapitação, fuzilamento, cadeira elétrica, câmara de gás.

\section{A Execução da Pena}

Atualmente, as execuções são feitas mediante a autorização do Ministro da Justiça (art. 475 do Código de Processo Penal). Assim, cabe a ele decidir o número de execuções, bem como indicar os condenados que serão executados (INTERNATIONAL FEDERATION FOR HUMAN RIGHTS, 2003, p.10). Uma vez que o Ministro da Justiça ordena a execução da pena de morte, ela deverá ser executada no prazo de 5 dias. $\mathrm{O}$ art.475 requer a ordem do Ministro da Justiça para a sentença ser executada, se o

7. Todas as pessoas devem ser respeitadas como indivíduos. $\mathrm{O}$ seu direito à vida, à liberdade, e a persecução da felicidade na medida em que não interfira com o bem-estar social, em consideração suprema da legislação e outros negócios governamentais. 
Ministro escolhe não executar a ordem, a execução é suspensa. Entre 1989 e 1993 houve moratória nas execuções porque o Ministro da Justiça que atuava durante esse período tinha posicionamento contrário a tal pena. O último ministro da Justiça, Sadakazu Tanigaki (dezembro 2012-setembro 2014) ordenou a execução de oito prisioneiros no período em que ocupou o cargo. (INTERNATIONAL FEDERATION FOR HUMAN RIGHTS, 2014, p.5). O art. 477 do CPP estabelece que a execução deverá ser feita com a presença do promotor e seu assistente e um agente penitenciário ou seu representante e que nenhuma outra pessoa poderá estar presente no local da execução exceto quando houver permissão do promotor ou do agente penitenciário. A pena de morte no Japão é prevista para crimes que implicam ou não na morte das vitimas ${ }^{8}$. Entretanto, na prática, ela tem sido usada apenas nos casos de homicídio, latrocínio e estupro seguido de morte (SHER, 2011, p.644).

8. Os crimes que implicam em pena de morte são Homicídio: Matar outra pessoa é crime punível com a pena de morte. Contudo, em termos práticos, o Japão somente impõe a pena de morte se o homicídio estiver acompanhado de fatores agravantes, incluindo várias vítimas e o cometimento de outros crimes.(Código Penal, art.199); Outros crimes que resultam em morte: $\mathrm{O}$ roubo seguido de morte (latrocínio) na cena do crime do roubo é punível com a pena de morte. (Código penal, art. 240) O estupro concomitante ao roubo que cause morte é punível com a pena de morte(Código Penal, art.241). A poluição de água potável pública que cause a morte de uma pessoa é punível com a pena de morte(Código Penal, art. 146). Causar a morte de uma pessoa no cometimento de um capotamento ou destruição de um trem ou bonde ou durante a virada de uma embarcação (emborcamento) que cause a morte de uma pessoa é punível com a pena de morte(Código Penal, art.126). A direção perigosa, que leve ao capotamento de um trem ou bonde ou virar uma embarcação (emborcamento) que cause a morte de outra pessoa é punível com a pena de morte.(Código Penal,arts. 125-127). Participar de um duelo que cause morte também é punível com a morte.Lei Especial;Crimes relacionados ao terrorismo que resultem em morte;Sequestrar um avião que cause a morte e destruição de aeronaves que resulte em morte são puníveis com a pena de morte; Crimes relacionados ao terrorismo que não resultem em morte; Destruição por explosivos e uso ilegal de explosivos são condutas puníveis com a pena de morte.(Código Penal, art.117). Incêndio que não resulte em morte (Código Penal, art.108); Incendiar um edifício, trem, bonde, embarcação ou mina em que uma pessoa esteja, ou que seja usada como moradia é conduta punível com a pena de morte.(Código Penal, art.108 ); Traição (Código Penal, arts. 81, 82, 77(1)(i); Instigar agressão estrangeira (Código Penal, art.81) contra o Japão também acarreta a pena de morte. Auxiliar um inimigo por meio de serviço militar direto ou que, de alguma forma, permita vantagem militar é punível com a pena de morte(Código Penal, art.82). Liderar uma insurreição é conduta punível com a pena de morte.(Código Penal, art.77(1)(i); Outros crimes que não resultem em morte; Os crimes a seguir são puníveis com a morte: Dar causa 'a inundação que danifique um edifício, trem, bonde ou mina que seja usada como moradia ou onde pessoas estejam presentes é punível com morte.(Código Penal, art.119); Detonar um explosivo e que, assim, danifique um edifício, trem, bonde, embarcação ou mina que seja utilizada como moradia ou onde outras pessoas estejam presentes é punível com a morte.(Código Penal, arts. 108, 117(1); Causar dano em estrutura náo habitada por violação de domicílio.(Código Penal, art. 119). Disponível em http://www.deathpenaltyworldwide. org/country-search-post.cfm?country=Japan. Acesso em 20 outubro 2014. 
Os condenados à morte podem requerer um novo julgamento, mas os requisitos necessários para fazer o pedido são restritos, exige-se que novas provas que provem a inocência do réu sejam apresentadas ou que se comprove que a decisão foi fundamentada em provas equivocadas. É possível fazer o pedido de um novo julgamento inúmeras vezes, mas é muito raro que um novo julgamento seja concedido. (FÉDERATION INTERNATIONALE DES LIGUES DES DROITS DE L'HOMME, 2003, p.16). A aplicação da pena passou a ser mais restrita com a imposição do critério Nagayama. Norio Nagayama foi um condenado à morte que se tornou célebre tanto pelos crimes que cometeu quanto pelo legado literário que construiu durante a sua vida no cárcere. Ele foi preso após cometer quatro homicídios, entre 11 de outubro de 1968 e 5 de novembro de 1968. O primeiro assassinato ocorreu no Hotel Prince em Tóquio quando ele acertou dois tiros na cabeça do vigia, Kiminori Nakamura, em uma tentativa de assalto. Em uma segunda tentativa de roubo, em 14 de outubro, ele matou um outro vigia, Tomejiro Kamitsu próximo ao templo Yasaka em Quioto. O terceiro incidente ocorreu no dia 27 de outubro no qual ele matou o motorista de táxi, Tetsuhiko Saito, em Hakodate. E por fim, o último crime foi cometido em Nagoya no dia 5 de novembro quando outro motorista de táxi, Masaki Ito, foi morto durante um assalto. A soma irrisória que ele conseguiu após os quatro crimes foi de 16 mil ienes, cerca de 440 reais. (MÉTRAUX, 2009, p.283). Essa série de crimes ganhara tamanha repercussão que constituiu um novo marco para o estabelecimento de critérios para a execução dos condenados. $\mathrm{O}$ critério consiste no exame cuidadoso dos seguintes fatores:

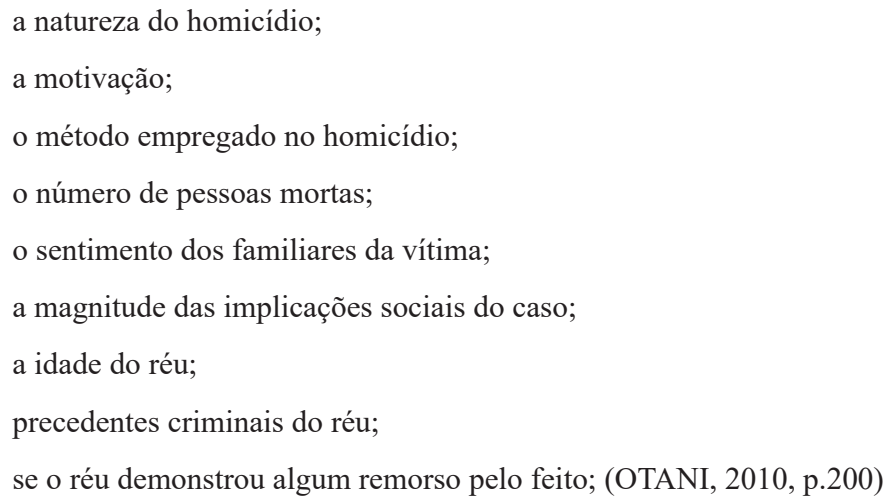

Nagayama tentou defender-se ao fazer a ligação da sua motivação do latrocínio com a pobreza e ignorância vivenciadas na infância conforme relatado no seu livro de grande vendagem Muchino namida (Lágrimas da Ignorância). A sua defesa foi considerada em juízo e a Suprema Corte de Tóquio comutou a sua pena de morte para pérpetua em 1981 no qual sentenciou que "O governo deveria ter poupado o acusado da pobreza e seria injusto ignorar a ausência de políticas apropriadas que visassem o 
bem-estar e responsabilizá-lo por tudo." (OBARA, 2013, p.44). Entretanto, essa decisão foi revertida e Nagayama foi executado em 1997.

Em julho de 2009, o judiciário japonês implementou o Tribunal do Júri para determinados tipos penais (COREY e HANS, 2010, p.90). Este sistema estabelece que seis cidadãos determinem em conjunto com três juízes profissionais a culpabilidade ou inocência em uma sentença apropriada (SAIKÔ SAIBANSHÔ). A culpabilidade deve ser pronunciada apenas quando os cidadãos "estão certos de que não há lugar para dúvida" (HIRANO, 2012). Se o veredicto unânime não for alcançado, a decisão majoritária predomina desde que esta inclua o voto de pelo menos um juiz profissional e um jurado. O objetivo do Tribunal do Júri é a criação de "uma justiça mais ágil, amigável e confiável" e "aumentar o entendimento da confiança e entendimento do público geral em relação ao sistema judiciário (SAIKÔ SAIBANSHÔ)."Na prática, em comparação com os julgamentos que eram feitos exclusivamente por juízes profissionais, o júri tem produzido sentenças mais severas com relação aos réus acusados de crimes sexuais assim como para aqueles que causaram lesões seguidas de morte (NIKKEI KEIZAI SHINBUN, 2012). Esse sistema possibilita a maior participação dos cidadãos no restabelecimento da ordem social, mas em muitos casos causa um grande fardo psicológico para os jurados.

\section{A retenção da pena}

Recentemente, a pena capital tem sido executada com menor freqüência no Japão, e em 2014, foram apenas três execuções. (AMNESTY INTERNATIONAL 2015, p.62). O baixo número suscita o questionamento a respeito dos motivos para manter tal pena no sistema legal japonês. Afinal, se a aplicação é tão baixa seria necessário mantê-la? Uma das explicações mais utilizadas para a manutenção da pena baseia-se em pesquisas de opinião pública que apontam que a grande maioria da população é favorável a manutenção da pena de morte. As pesquisas realizadas pelo governo em 2009 apontam 85.5\% de aprovação (OBARA, 2013, p.29).

Uma razão para defesa da pena de morte seria a de que a ameaça de morte previne o crime uma vez que o ser humano tem o instinto de preservação da própria vida e não cometeria atos que pudessem colocá-la em situação de risco. Apesar da antiguidade dessa pena, a justificativa de prevenção do crime é relativamente recente. Antes da necessidade de justificá-la, a pena de morte foi imposta para uma grande variedade de crimes e não se questionava a sua moralidade. A teoria da prevenção, portanto, surgiu apenas nos últimos dois ou três séculos e as sociedades dessa forma foram obrigadas a criar justificativas plausíveis para a sua existência uma vez que as punições corporais estavam caindo em desuso (ARCHER, GARTNER, BEITTEL, 1983, p.992). Para que a pena de morte funcione como fator preventivo para a ação do criminoso, deve-se partir do pressuposto que o criminoso saiba exatamente quais são as penas aplicáveis aos seus atos, o que não ocorre necessariamente. Os condenados 
tendem a não ter conhecimento de quais tipos penais resultam em pena de morte ou até mesmo se o país em que vivem existe tal pena. Seria necessário, portanto, que os criminosos realmente soubessem quais tipos penais são passíveis de pena de morte (ARCHER, GARTNER, BEITTEL, 1983, p.995). Outros fatores que podem contribuir para a prevenção do crime são a severidade da pena, a certeza da punição e a celeridade da sua aplicação.

Apesar de vários argumentos servirem para a continuação de sua existência, um dos argumentos mais razoáveis para defender a sua abolição é que o erro na condenação é irreversível. Alguns retencionistas, entretanto, argumentam que o erro no julgamento não é peculiar somente à pena capital, ocorrendo em todos os tipos de penalidade (DANDO, 1996, p.13). Entretanto, caso o erro seja descoberto antes ou após a pena ser executada não há indenização pecuniária que possa recuperar o tempo perdido na prisão ou o erro após a morte do condenado. Um exemplo proeminente é de Iwao Hakamada, um boxeador profissional que passou 48 anos no corredor da morte após receber a possibilidade de um novo julgamento em 2014. Ele havia sido condenado pela morte do seu ex-chefe, esposa e seus dois filhos em 1966 e confessou o crime após 20 dias de interrogação da polícia, mas alegou que fez a confissão sob tortura da polícia. A principal evidência do crime foi a roupa usada pelo assassino que tinha vestígios de sangue. Após testes de DNA, constatou-se que a roupa não havia sido usada por Hakamada, o que veio a expor o erro no inquérito policial (AMNESTY INTERNATIONAL, 2014). Mas, a sua condenação na época foi feita por dois do grupo de três juízes, sendo ele, então, condenado à morte. Kumamoto Norimichi, o juiz com voto vencido, escreveu 360 páginas na sua opinião dissidente e após um ano deixou o Judiciário. Em 2007, ele finalmente veio à público para explicar que as peças de evidência usadas contra Hakamada não faziam sentido, por exemplo, as calças manchadas de sangue não eram do tamanho do acusado. A decisão pela condenação do réu foi baseada somente na confissão extraída sob tortura. Kumamoto requereu um novo julgamento para Hakamada em 2007 (SHER, 2011, p.650) o que foi finalmente concedido em 2014 pela Corte da província de Shizuoka.

A opinião pública é influenciada por alguns fatores, em especial, o sexo, a idade, a orientação política, o momento em que a pesquisa de opinião foi realizada e o enquadramento das perguntas. Esses fatores ajudam a explicar porque as pesquisas de opinião realizadas pelo Ministério da Justiça japonês tendem a produzir os resultados favoráveis à pena de morte. No Japão, dentre as pessoas que responderam o questionário pôde ser verificado que aqueles com visão mais conservadora eram contrários à abolição da pena ao contrário dos que tinham visão mais progressista que tiveram posicionamento oposto a aqueles. (SATO, [200-], p.15). O governo japonês escolhe deliberadamente momentos de comoção, em especial, após crimes notórios 
ocorridos em 1989, como o caso do assassinato das pequenas garotas ${ }^{9}$ e do assassinato de uma garota no qual o corpo foi ocultado em um tambor ${ }^{10}$ (SATO, [200-], p.15).

$\mathrm{O}$ enquadramento das pesquisas pode influenciar as respostas dos entrevistados uma vez que as alternativas dadas como respostas podem modificar o posicionamento de apoio à pena de morte. Por exemplo, ao perguntar se o entrevistado é favorável à pena de morte ao invés de perguntá-lo se a pena de morte é mais adequada do que a prisão perpétua reflete-se consentimento e não preferência dentre outras alternativas. Da mesma forma, na pesquisa de opinião feita pelo governo japonês em 2004, 81\% dos entrevistados se demonstravam favoráveis à pena de morte. No entanto, foram dadas apenas três alternativas de resposta que não incluíam penalidades alternativas. Por outro lado, em uma pesquisa de opinião conduzida pela emissora NHK demonstrou que apesar de $63 \%$ dos entrevistados serem favoráveis à pena de morte, $57 \%$ respondeu que não seria contrária à comutação dessa pena para pena perpétua, caso não houvesse liberdade condicional. (SATO, [200-], p.16). Por esses motivos, a confiabilidade nos resultados das pesquisas de opinião é prejudicada e apresenta fragilidade como justificativa para a retenção da pena de morte.

\section{Conclusões}

A pena de morte no Japão foi preservada durante a maior parte da história do país. Apesar da oposição a ela ser forte na sociedade civil e ambiente acadêmico, as pesquisas de opinião feitas pelo Ministério da Justiça demonstram um alto índice de aprovação popular. Ficou demonstrado, porém, que tais pesquisas podem manipular os resultados a favor da posição retencionista. No passado, a pena de morte era a punição mais recorrente para uma grande variedade de crimes, desde pequenos furtos até os crimes hediondos. Durante um longo período não havia sequer necessidade para justificação de aplicação de tal pena.

Com o surgimento de instrumentos internacionais de direitos humanos e à adesão de muitos países a padrões estabelecidos por tratados internacionais, que propõem respeito ao direito à vida, a sociedade internacional considera cada vez menos a pena de morte como uma penalidade aceitável. O Japão, nesse sentido, apesar de ser signatário de diversos tratados de direitos humanos e ter dispositivos constitucionais que dão margem à interpretação de ilegalidade da pena de morte, não a aboliu do seu sistema penal.

9. Entre 1988 e 1989, Tsutomu Miyazaki mutilou e assassinou 4 meninas entre 4 e 7 anos de idade. Ele fez sexo com os corpos e comeu parte das terceira e quarta vítimas. O caso chocou a província de Saitama. Em 2006 a Suprema Corte manteve a sua decisão original de condená-lo a morte. Ele foi executado em 17 de junho de 2008.

10. Quatro menores submeteram uma jovem de 17 anos em cárcere privado por 41 dias. A garota morreu após ser repetidamente estuprada e espancada. Eles ocultaram o cadaver um um tambor preenchido com concreto. O caso atraiu a atenção da mídia pela atrocidade e porque os réus tinham menos de 18 anos e por isso a pena de morte não foi aplicada no caso deles. 
A retenção de tal pena depende de fatores complexos ligados ao sigilo dos detalhes da sua execução, que obsta a população de tomar conhecimento para ter um melhor juízo de valor, a própria estrutura do Judiciário e da crença em que a pena poderá prevenir o cometimento de crimes. O baixo número de execuções poderia gerar dúvidas sobre a necessidade da aplicação de tal pena, mas esse argumento não é destituído de oposição uma vez que o inverso também poderia ser alegado. Há baixa criminalidade porque a ameaça da pena de morte previne os indivíduos de cometerem crimes.

Com a instauração do regime de tribunal de júri, a responsabilidade de decidir pela morte do réu recai também sobre o júri composto por cidadãos comuns, ocasionando discussões a respeito do fardo psicológico causado pelas decisões favoráveis à execução do réu. Não obstante o surgimento dessa natureza de discussão e dos esforços conjuntos da academia e de organizações não governamentais, a pena de morte tem possibilidade mínima de ser abolida em curto e em médio prazo.

\section{Referências Bibliográficas}

ABE, Kohki. Aragau shisô/ Heiwawo tsukuru chikara ( $O$ pensamento combativo- a força para criar a paz), $1^{\mathrm{a}}$ ed., Tóquio: Fukishobô, 2008.

AMNESTY INTERNATIONAL. Death Sentences and Executions, Londres, 2015. 76 p. Disponível em: <http://www.amnestyusa.org/pdfs/ DeathSentencesAndExecutions2014_EN.pdf $>$. Acesso em: 20 jul. 2015.

ARCHER, Dane, GARTNER, Rosemary, BEITTEL, Marc. Homicide and Death Penalty: a cross - national test of a deterrence hypothesis. The Journal of Criminal Law and Criminology, Chicago, v. 74, n. 3, p. 991-1013, 1983.

CHUKYO HOGAKU. Shikei sentakuno kijyun- Nagayama Norio hanketsu yoriKeiji hanrei kenkyu (Os padrões de escolha da pena de morte- A partir da decisão de Norio Nagayama- Pesquisa de jurisprudência penal) Chukyo university , Nagoya, v. 21, n.2, p.139-151, fevereiro, 1987.

COREY, Zachary e HANS, P. Valerie. Japan's new lay judge system: deliberative democracy in action? Asia Pacific Law and Policy Journal, Manoa, v.12, n.1, p.72-94, 2010.

DANDO, Shigemitsu. (1996) Toward the Abolition of Death Penalty, Indiana Law Journal, Bloomington, v.72, n.7, p. 7-19, April,1996.

HIRANO, Heiji. Lay judge death sentences must be unanimous: JFBA, The Japan Times. Disponível em: <http://www.japantimes.co.jp/ news/2012/03/25/news/lay-judge-death-sentences-must-be-unanimousjfba/\#.VE8WiOO9nDt.>Acesso em: 18 jul. 2015. 
HUMAN RIGHTS COMMITTEE, Concluding observations on the sixth periodic report of Japan, 2014. Disponível em: <http://hrn.or.jp/eng/wpcontent/uploads/2014/08/Concluding-Observations.pdf $>$. Acesso em: 15 ago. 2015.

FÉDERATION INTERNATIONALE DES LIGUES DES DROITS DE L'HOMME. Shikei: Minshushugi kokkani aru majiki kôi, Paris, v. 359, n. 3, maio, 2003. Disponível em: < https://www.fidh.org/IMG/pdf/jp359j. pdf>. Acesso em: 20 jul.2015.

HOMUSHÔ. Shiryô (documento) no.18 [201-]. Desenvolvido pelo Ministério de Justiça do Japão. Disponível em: <http://www.moj.go.jp/keiji1/ keiji12_00056.html>. Acesso em: 10 set. 2015.

INTERNATIONAL FEDERATION FOR HUMAN RIGHTS. Death penalty in Japan: a practice unworthy of democracy, 2003, Disponível em: $<$ http:// www.fidh.org/IMG/pdf/jp359a.pdf>. Paris, v.359, n.2. Acesso em: 15 set. 2015.

INTERNATIONAL FEDERATION FOR HUMAN RIGHTS, Death penalty in Japan. Denial of the right to life and other human rights violations, 2014. Disponível em: <http://www.fidh.org/IMG/pdf/20141010_japan_dp_report_en.pdf $>$. Acesso em: 13 set. 2015 .

JOHNSON, David T. Japan's secretive death penalty policy: contours, origins, justifications, and meanings, Asian-Pacific Law \& Policy Journal, Manoa, v.7, n.2, summer, p. 62-124, 2006.

KIM, Chin. Capital Punishment in the United States and Japan: constitutionality, justification and methods of infliction. Loyola of Los Angeles International and Comparative Law Journal, Los Angeles, v.11, n.2, p.253-279, 1989.

SATO, Mai. Public opinion and death penalty in Japan. [200-]. Disponível em: $<$ http://www.westminster.ac.uk/_data/assets/pdf_file/0004/43429/v.4_4. pdf $>$. Acesso em: 10 set. 2015.

NICHIBENREN. Recommendations on the capital punishment system, 2002. Disponível em: <http://www.nichibenren.or.jp/library/en/document/ data/INT03_10_PS.pdf>. Acesso em: 26 ago. 2015.

NICHIBENREN. Shikeiha donoyôni shikkô sarerunoka (Como a pena de morte é executada). Disponível em: $<$ http://www.nichibenren.or.jp/activity/ criminal/deathpenalty/q06.html $>$. Acesso em: 8 de jul. 2015. 
NIKKEY KEIZAI SHINBUN. Saiban'in seido seihanzaini kibishikushikkôkara san'nen. (Sistema do Tribunal do Júri é severo com relação a crimes sexuais- 3 anos de aplicação) Disponível em: <http://www.nikkei. com/article/DGXNASDG1402R_U2A510C1CR8000/> . Acesso em: 17 set. 2015.

MÉTRAUX, Daniel A. The Nagayama criteria for assessing the death penalty in Japan: reflections of a case suspect. Southeast Review of Asian Studies, Ashland, v. 31, p.282-89, 2009.

OBARA, Mika. Government justification for capital punishment in Japan: case study of de facto moratorium period from 1989 to 1993 . Doctoral thesis. Loughborough, Loughborough University, 2013.

OTANI, Kyoko. Soredemo karewo shikeini shimasuka? Abashirikara Peruhe-harukanaru tabi. (Mesmo assim, o condenam à morte? De Abashiri ao Peru-a última viagem) $1^{a}$ ed. Tóquio: Gendaikikakushitsu, 2010.

SAIKÔ SAIBANSHÔ. Desenvolvido pela Suprema Corte do Japão. Disponível em: $<$ http://www.saibanin.courts.go.jp/introduction/>. Acesso em 13 set. 2015.

SAKURAI, Satoshi. Shikei sonhatsuronni okeru "shikei shikkônin" no ichini tsuiteno- kôsatsu- Nihonno koubunshoni miru shikeishikkô genbano seiseito shômetsu (A discussão sobre a posição do executor da pena de morte no discurso retencionista- o gênese e a extinção do local de execução da pena de morte de acordo com os documentos públicos japoneses) Core Ethics, Quioto, v.4, p.93$103,2008$.

SATO, Mai. Public opinion and death penalty in Japan. Disponível em: $<\mathrm{https} / /$ www.westminster.ac.uk/_data/assets/pdf_file/0004/43429/v.4_4.pdf> [2000-]. Acesso em: 10 jul.de $20 \overline{15}$.

SCHMIDT, Petra. Capital punishment in Japan. $1^{\mathrm{a}}$ ed. Leiden: Brill, 2001.

SHER, Elizabeth M. Death penalty sentencing under the lay assessor system: avoiding the avoidable through unanimity. Pacific Rim Law \& Policy Journal Association, Seattle, v. 20, n.3, p.635-658, June, 2011.

STEENSTRUP, Carl. A History of Law in Japan until 1868. $1^{\text {st }}$ ed. Leiden: Brill, 1991.

TAKEDA, Kazuo. Shishaha mata tatakau- Nagayama Norio saibanno Shinsoto shikeiseido (O morto ainda luta- $\mathrm{O}$ sistema de pena de morte e a verdade no julgamento de Norio Nagayama) Tóquio: Meiseki shoten, 2010. 